\title{
Segmental noun/verb phonotactic differences are productive too
}

\author{
Jennifer L. Smith*
}

\begin{abstract}
Not all statistical patterns in a speaker's lexicon are acquired productively, and it has been proposed that distinguishing between those patterns that are productive and those that are not serves as a source of evidence for the existence of learning biases in the grammar (Becker et al. 2011). A cross-linguistic survey of categorical noun/verb phonotactic differences finds that most of them involve prosodic patterns, such as stress or tone, not segmental ones - but does this typological asymmetry actually result from a learning bias against segmental noun/verb differences? English provides a testing ground for this question, as the lexicon has statistical differences between noun and verb phonotactics involving not only stress, a prosodic property, but also fricative voicing and vowel backness, which are segmental properties. A nonce-word noun/verb categorization experiment finds that adult English speakers apply all three patterns productively, even the segmental ones. Moreover, evidence for productive knowledge is found even when the effect of existing morphological alternations (such as the stress alternation seen in pérmit $\mathrm{N}_{\mathrm{N}} /$ permit $\mathrm{v}$ ) is controlled for. These results contribute to a growing body of evidence that gaps in language typology do not necessarily correspond to patterns that are unlearnable.
\end{abstract}

Keywords. phonotactics; productivity; lexical categories; category-specific phonology; typological gaps; surfeit-of-the-stimulus paradigm

1. Introduction. Nouns and verbs can have different phonotactics within the same language (Kelly 1992; Bobaljik 2008). For example, in Mono, tone is contrastive for nouns but predictable for verbs (Olson 2005). In English, disyllabic nouns are more likely to be trochees, while disyllabic verbs are more likely to be iambs (Kelly \& Bock 1988). Crucially, while some apparent noun/verb differences reduce to free/bound differences, this is not a general explanation (Smith 2011), so the phonological grammar must be able to represent - and language learners must be able to acquire - distinct phonological patterns for nouns and verbs. (This is true also for further lexical categories and subcategories; see, e.g., Becker (2003) on adjectives, Walker (1984: 96) and Jaber (2011) on proper nouns, and Smith (2014) on unaccusative verbs.)

However, it is an open empirical question as to whether there are differences in segmental phonotactics between nouns and verbs. A typological survey of categorical noun/verb phonotactic differences (Smith 2011) finds that segmental asymmetries are rare. As seen in (1), prosodic patterns such as stress, pitch accent, tone, and word size or prosodic shape are attested, but segmental characteristics such as voicing or nasality are strikingly absent; the two cases of what their sources describe as diachronic segment deletion in Paamese (Crowley 1997: 243-244) and Mohawk (Postal 1968) appear open to reinterpretation as effects of syllable-structure

* Many thanks to Elliott Moreton, Katya Pertsova, Adam Albright, Michael Becker, Sarah Finley, Sharon Inkelas, Emily Moeng, Charlie O'Hara, Amy Reynolds, Stephanie Shih, and audiences at LSA 2016, LAGB 2014, and the UNC-CH Phonology/Phonetics Research Group for comments and discussion on this and related material. Thanks also to Chris Wiesen of the Odum Institute for Research in Social Science, UNC-CH, for statistical consultation. Author: Jennifer L. Smith, University of North Carolina, Chapel Hill (jlsmith@email.unc.edu). 
requirements on sonority or segment sequencing, which would plausibly fall under prosodic effects as well. ${ }^{1}$

(1) Categorical noun/verb phonotactic differences (see Smith 2011 for discussion)

a. Stress

b. Pitch accent

c. Tone

d. Word size or prosodic shape

e. Diachronic segment deletion (?)
Spanish (Harris 1983)

Hebrew (Becker 2003)

Lenakel (Lynch 1975, 1978)

Japanese (McCawley 1968)

Proto-Korean (Whitman 1994)

Sibe [Xibe] (Kubo 2008)

Ancient Greek (Devine \& Stephens 1994)

Mono (Olson 2005)

Proto-Bantu (Kisseberth \& Odden 2003)

Ewe (Ansre 1961)

Lamang (Wolff 1983)

Hebrew (Becker 2003)

Mbabaram (Dixon 1991)

Chuukese (Muller 1999; Goodenough \& Sugita 1980)

Chukchee, Koryak (Krause 1979)

Arabic (Ryding 2005)

Itelmen (Bobaljik 1998, 2008)

Paamese (Crowley 1997)

Mohawk (Postal 1968)

There are also gradient noun/verb differences, some of which are segmental. For example, in English, disyllabic nouns are more likely to be trochees, while disyllabic verbs are more likely to be iambs (Chomsky \& Halle 1968). This pattern is illustrated in (2) (Kelly \& Bock 1988, reporting stress data from Francis \& Kučera 1982). The differences between nouns and verbs in (2)(a) and (2)(b) are both significant $\left(\chi^{2}(1)=1757.56, p<0.0001 ; \chi^{2}(1)=1241.1, p<0.0001\right.$; Yates chi-square, corrected for continuity).

(2) Gradient noun/verb stress differences in English (Kelly \& Bock 1988: 391)

\begin{tabular}{llrrr}
\hline a. & Disyllables used only as... & Total & Initial stress & Final stress \\
\cline { 2 - 5 } Nouns & 3002 & $94 \%$ & $6 \%$ \\
Verbs & 1021 & $31 \%$ & $69 \%$ \\
\cline { 2 - 5 } b. & All disyllabic items that are... & Total & Initial stress & Final stress \\
\cline { 2 - 5 } & Nouns & 4218 & $89 \%$ & $11 \%$ \\
Verbs & 1676 & $46 \%$ & $54 \%$ \\
\hline
\end{tabular}

Another phonotactic difference between nouns and verbs in the English lexicon involves fricative voicing. Nouns are more likely than verbs to end in a voiceless fricative (Albright 2008;

1 O'Hara (to appear) has recently argued that Klamath has a segmental noun/verb asymmetry: short /e/ is banned from non-initial position in verbs, but is allowed in the same position in nouns. 
Jespersen 1942), a pattern that is related to the existence of N/V pairs such as $h o u[\mathrm{~s}] e_{\mathrm{N}}, h o u[\mathrm{z}] e_{\mathrm{V}}$ (see further discussion of morphological factors in $\$ 3.3$ below).

Finally, a third pattern found in English is one involving vowel backness: nouns are more likely than verbs to have a back vowel in the main-stress syllable (Sereno \& Jongman 1990; Berg 2000). This pattern is illustrated in (3), with data from the 1000 most frequent nouns and verbs in CELEX (Baayen et al. 1995) that are are monomorphemic and have a front or back main-stress vowel, as reported by Berg (2000). The difference between nouns and verbs in (3) is significant $\left(\chi^{2}(1)=5.21, p=0.0225\right.$; Yates chi-square, corrected for continuity), although numerically the difference between nouns and verbs is smaller than for the stress asymmetry in (2).

(3) High-frequency nouns and verbs with front or back main-stress vowels (Berg 2000: 277)

\begin{tabular}{llr}
\hline & Front vowel & Back vowel \\
\hline Nouns & $206(45.7 \%)$ & $245(54.3 \%)$ \\
Verbs & $249(53.4 \%)$ & $217(46.6 \%)$ \\
\hline
\end{tabular}

The question remains, however, whether these three noun/verb phonotactic differences found in the English lexicon are productive. That is, are they part of the linguistic competence of an English speaker?

Previous nonce-word experiments testing for productivity of noun/verb differences in English have produced mixed results. Stress differences were found to be productive in experiments involving both oral production of nonce words presented in noun versus verb sentence frames (Kelly \& Bock 1988; Guion et al. 2003) and forced-choice stress preference judgments for nonce words in noun versus verb sentence frames (Guion et al. 2003). In contrast, no effect of productivity was found for segmental patterns in experiments that elicited wordlikeness judgments for nonce words presented once again in noun versus verb sentence frames (Albright 2008).

On the other hand, there is some evidence for the psychological reality of noun/verb segmental differences in existing words of English. Sereno \& Jongman (1990) found that reaction times were faster, for both a noun-versus-verb labeling task and for a general lexicaldecision task, when nouns had back vowels and verbs had front vowels in accordance with the lexical asymmetry in (3) (although this effect was found for high-frequency words only).

Finally, recent experimental evidence using stimuli other than nonce words to look for productivity of segmental noun/verb differences in English has been inconclusive. In an artificiallanguage experiment, English-speaking participants were exposed to 'languages' in which nouns and verbs differed in terms of either legal vowel inventory, which is a segmental pattern, or legal stress-pattern inventory, which is a prosodic pattern (Smith 2014). The prosodic pattern was learned more successfully than the segmental pattern. There may, however, have been a confounding factor of complexity, as the prosodic pattern involved inventories of two stress patterns versus just one (simple contrast/no contrast), while the segmental pattern involved inventories of five vowels versus three (complex contrast/simple contrast). Indeed, essentially the opposite result was found in a set of emergent-effects experiments with English nonce blends that probed for category-specific faithfulness, comparing nouns with verbs and proper nouns with common nouns (Moreton et al. 2016). The results did show category-specific patterns of resistance to segmental deletion - and the magnitude of the segmental effect was actually 
stronger than that for stress. This finding may thus be evidence that the grammar can indeed represent a category-specific difference in segmental phonology. It is worth noting, however, that the phonological pattern under consideration was segmental deletion rather than a pattern involving the featural characteristics of segments, and so it still straddles the boundary between segmental and prosodic effects.

Given the conflicting or inconclusive results from previous studies, the experiment reported here was designed to probe whether the noun/verb segmental differences involving fricative voicing and vowel backness that are seen in the English lexicon are actually part of adult English speakers' productive phonological knowledge (see, e.g., Becker et al. 2011 on the surfeitof-the-stimulus paradigm), and if so, how the productivity of these patterns compares to the productivity of noun/verb stress differences. This study uses a potentially more sensitive methodology than the wordlikeness judgment task used by Albright (2008), which did not find evidence of productivity for segmental patterns. The task used here is forced-choice assignment of members of a minimally contrastive pair of nonce words to the explicit category labels noun and verb.

2. Experiment. In this study, participants were presented with nonce-word minimal pairs and were asked to label each pair as 'noun...verb' or 'verb...noun' in a two-alternative forced-choice design. As noted above, the use of minimally contrastive nonce-word pairs was intended to emphasize noun/verb comparisons in the hopes that this would make participants more sensitive to potential phonological differences between the two categories. The experiment was completed by 80 English-speaking adults in the United States, recruited through the online labor exchange Amazon Mechanical Turk (Sprouse 2011).

The experiment began with three practice items, which were pairs of real English words with unambiguous category membership, such as cottage $\mathrm{N}_{\mathrm{N}}$ versus vanish $\mathrm{v}$. These practice items both introduced participants to the category-labeling task and also served as a diagnostic pretest to confirm that each participant could accurately identify actual nouns and verbs. (Participants who did not answer all three practice items correctly were not permitted to continue with the experiment.)

The experiment stimuli were 36 nonce-word pairs in three conditions: stress, fricatives, and vowels (see Appendix A for a complete list of stimuli). Twelve pairs consisted of disyllabic nonce words that differed in stress (['pel.tækt pel. 'takt] $)$. These stress pairs served as a control condition - they were identical to stimuli used in previous nonce-word experiments that had found a productivity effect for stress on English speakers' noun/verb judgments (Kelly 1988; Guion et al. 2003). In addition, twelve pairs differed in the voicing of a final fricative

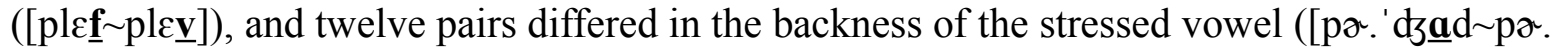
'dzad]). The fricative and vowel pairs included monosyllables, trochees, and iambs. Presentation order within pairs was counterbalanced across participants, and pairs were sequenced in a different random order for each participant. The predicted responses to each stimulus type, under the hypothesis that participants have productive knowledge of the noun/verb asymmetries in the lexicon, are summarized in (4). 
(4) Predicted category assignments if lexical noun/verb asymmetries are productive

\begin{tabular}{|c|c|c|}
\hline Condition & Noun & Verb \\
\hline Stress items & ['pel.tækt] & [pel.'takt] \\
\hline Fricative voicing items & {$[\mathrm{pl} \varepsilon \mathbf{f}]$} & {$[p l \varepsilon \underline{\mathbf{v}}]$} \\
\hline Vowel backness items & [pr. 'd d $\underline{\mathbf{a}} \mathrm{d}]$ & [pr. 'dugd] \\
\hline
\end{tabular}

The experiment instructions and one example trial, as seen by participants, are reproduced in Appendix B.

3. Results and analysis. The results of the experiment were analyzed in two ways: by response, to determine how many responses overall conformed to each lexical pattern of noun/verb difference, and by participant, to determine how many participants gave pattern-conforming responses in a majority of trials. The by-participant analysis was included in case there turned out to be distinct categories of participants with conflicting response patterns, which might render the overall by-response patterns non-significant. Also, for reasons discussed in $\S 3.3$, separate analyses were carried out first for all experimental items, and then for what are characterized below as non-morphological items.

3.1. Results AND ANALYSIS FOR ALl ITEMS, BY ReSPONSE. One goal of the experiment was to determine whether the overall pattern of responses to the nonce-word noun/verb categorization task would conform to the noun/verb asymmetries for stress, fricative voicing, and vowel backness observed in the lexicon of English, as summarized above in (4). Table 1 and Figure 1 show the results of a generalized linear mixed model, fit by the Laplace approximation, for the analysis by response. This analysis models the probability that a given response will conform to the noun/verb patterns in the lexicon of English, in terms of each phonological pattern investigated (stress, fricatives, or vowels). Items and participants are included as random effects.

As seen in Table 1 and Figure 1, all three phonological patterns had an effect significantly greater than chance. That is, more responses mapped the stress, fricative voicing, or vowel backness pattern to a noun/verb pair as predicted by the asymmetry observed in the lexicon than would be expected due to chance.

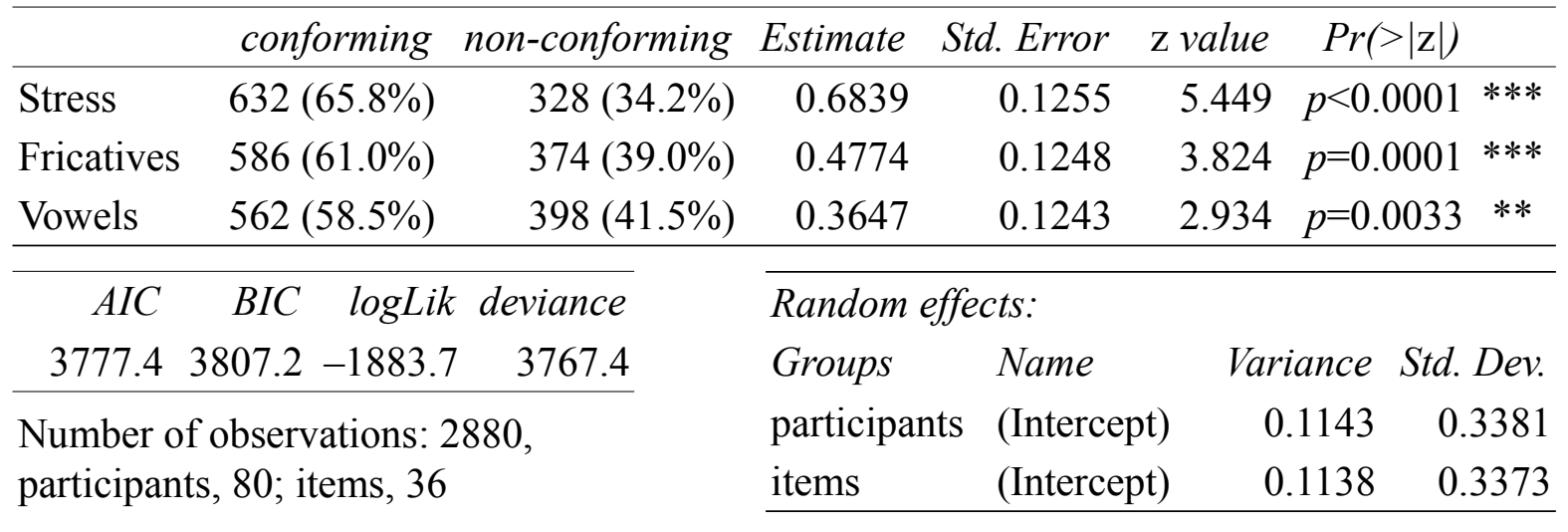

Table 1: Generalized linear mixed model, fit by the Laplace approximation, for the analysis by response (all items). 


\section{Proportion of conforming responses}

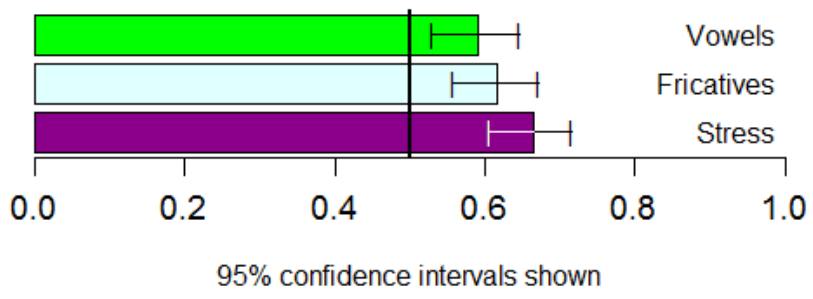

Figure 1: Results by response (all items). The coefficient estimates and standard errors from the logistic-regression model (see Table 1) were used to derive 95\% confidence intervals for each coefficient; logits were then converted to proportions.

As discussed in $\S 2$ above, the stress condition was considered a control condition in this experiment, since productive effects of stress asymmetries in nonce-word noun/verb categorization have been found in prior studies. Another goal of the experiment was therefore to compare the effects of the segmental patterns - fricative voicing and vowel backness - to that of stress. Table 2 shows the results of a generalized linear mixed model, fit by the Laplace approximation, that models the difference from stress in the probability that a given response will conform to the noun/verb asymmetry observed in the lexicon of English, in terms of segmental phonological pattern (stress vs. fricatives, stress vs. vowels). Again, items and participants are included as random effects.

\begin{tabular}{|c|c|c|c|c|c|c|c|}
\hline & conforming & non-conforming & Estimate $S$ & Std. Error & $\mathrm{z}$ value & \multicolumn{2}{|c|}{$\operatorname{Pr}(>|\mathrm{z}|)$} \\
\hline (Stress) & $632(65.8 \%)$ & $328(34.2 \%)$ & & & & & \\
\hline Fricatives & $586(61.0 \%)$ & $374(39.0 \%)$ & -0.2066 & 0.1686 & -1.225 & \multicolumn{2}{|c|}{$p=0.2205$ n.s. } \\
\hline Vowels & $562(58.5 \%)$ & $398(41.5 \%)$ & -0.3192 & 0.1683 & -1.897 & \multicolumn{2}{|c|}{$p=0.0578$} \\
\hline$A I C$ & BIC $\quad \log L i k$ & deviance & \multicolumn{5}{|c|}{ Random effects: } \\
\hline 3777.4 & $3807.2-1883.7$ & 3767.4 & \multirow{2}{*}{$\begin{array}{l}\text { Groups } \\
\text { participants } \\
\text { items }\end{array}$} & \multirow{2}{*}{$\begin{array}{l}\text { Name } \\
\text { (Intercept } \\
\text { (Intercept }\end{array}$} & \multicolumn{2}{|c|}{ Variance } & Std. Dev. \\
\hline $\begin{array}{l}\text { Number o } \\
\text { participan }\end{array}$ & $\begin{array}{l}\text { f observations: } 28 \\
\text { its, } 80 ; \text { items, } 36\end{array}$ & 880 & & & \multicolumn{2}{|c|}{$\begin{array}{l}0.1143 \\
0.1138\end{array}$} & $\begin{array}{l}0.3381 \\
0.3373\end{array}$ \\
\hline
\end{tabular}

Table 2: Generalized linear mixed model, fit by the Laplace approximation, for the difference from stress for fricative items and vowel items (all items, by response).

As Table 2 shows, the stress pattern and the fricative voicing pattern had the strongest effect, and the magnitude of these two effects was not significantly different. The vowel backness pattern was not quite as strong, and the magnitude of this effect was marginally significantly different from that of stress.

3.2. Results AND ANALysis FOR All items, By PARTicipant. The responses from all experiment items were also analyzed by participant, to determine whether the proportion of participants who gave a majority of responses conforming to the predictions in (4) was significantly greater than chance. 
Figure 2 shows, for each condition, the number of participants who gave $0,1, \ldots, 11$, or 12 conforming responses; participants with more than 6 conforming responses are classified as majority-conforming (colored bars), and those with fewer than 6 are classified as minorityconforming (gray bars).
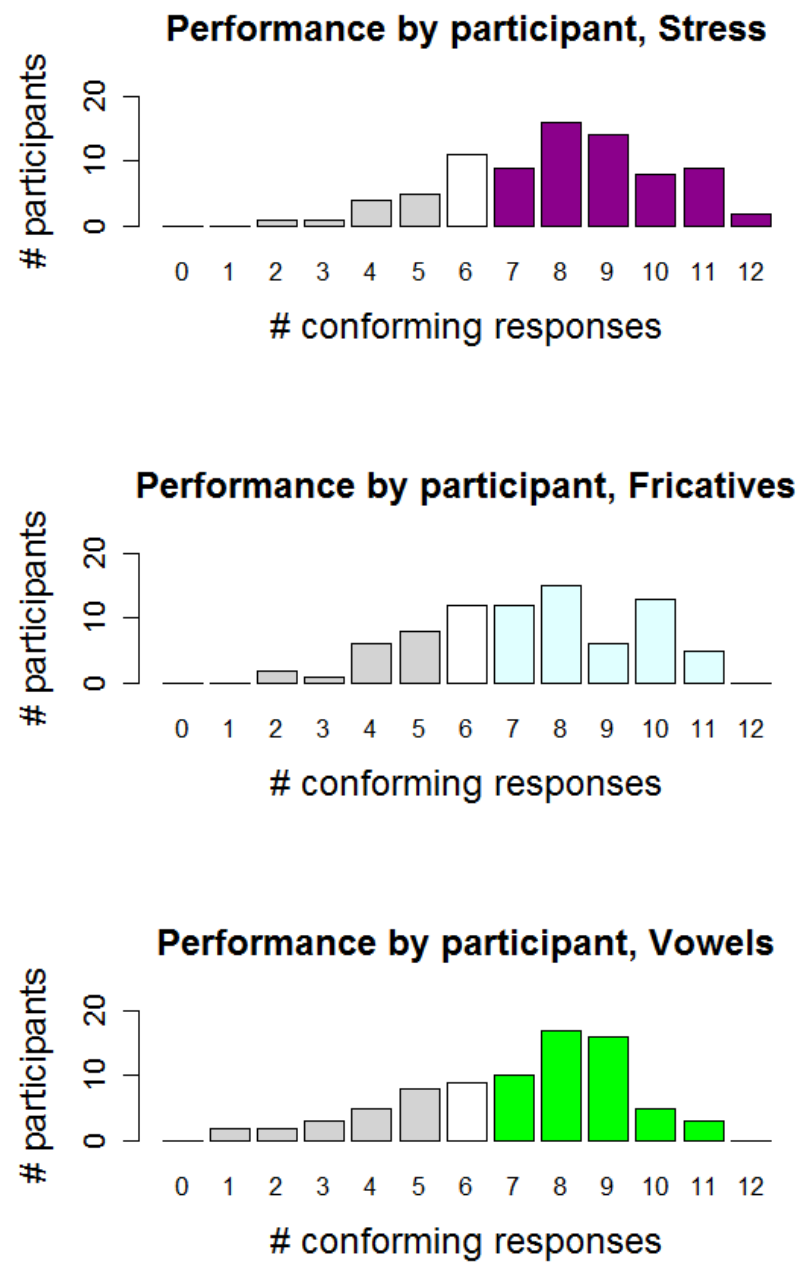

Figure 2: Number of participants in each condition who gave $0,1, \ldots, 11$, or 12 responses conforming to the noun/verb asymmetries in the lexicon of English.

Table 3 presents the results of an exact binomial test comparing the proportion of majorityconforming versus minority-conforming participants. (Participants with exactly 6 , or 50\%, conforming responses are not informative and are thus not included in this analysis.) 


\begin{tabular}{lrrrr}
\hline Condition & $\begin{array}{c}\text { Majority } \\
\text { conforming }\end{array}$ & $\begin{array}{r}\text { Minority } \\
\text { conforming }\end{array}$ & $\begin{array}{c}\text { Proportion } \\
\text { majority-conforming }\end{array}$ \\
\hline Stress & 58 & 11 & 0.84 & $<0.00001$ \\
Fricatives & 51 & 17 & 0.75 & 0.00002 \\
Vowels & 51 & 20 & 0.72 & 0.00015 \\
\hline
\end{tabular}

Table 3: Number of participants in each condition who gave a majority of responses

(vs. a minority) conforming to the pattern of noun/verb asymmetries in the lexicon of English. The $p$ values are from an exact binomial test (one-tailed).

The results summarized in Table 3 show that all three phonological patterns had an effect significantly greater than chance. That is, more participants mapped the pattern to a noun/verb pair as predicted by the lexical asymmetries than would be expected due to chance. Numerically, the effect of stress was strongest, then fricative voicing, then vowel backness.

3.3. RESULTS AND ANALYSIS FOR NON-MORPHOLOGICALLY SUPPORTED ITEMS ONLY. The analysis by response (§3.1) has found that the magnitude of the effect of vowel backness, while significantly greater than chance, was nevertheless marginally significantly less than that of stress, whereas the effect of fricative voicing was not significantly different from that of stress. The analysis by participant found a similar result numerically (although an explicit statistical comparison between the three different stimulus conditions was not performed) - namely, the proportion of majorityconforming participants was lowest for the vowel-backness condition. It seems, then, that English speakers' knowledge of the noun/verb asymmetry involving vowel backness is not as strongly productive as it is for the patterns involving stress and fricative voicing.

A potential explanation for why the effect of vowel backness might be comparatively small is that the vowel-backness asymmetry differs from the stress asymmetry and the fricative-voicing asymmetry in not being fully supported by evidence from morphologically related noun/verb pairs. That is, in the lexicon of English, there are actual noun/verb pairs that differ only in stress, such as pérmit $t_{\mathrm{N}} \sim$ permitv, or only in fricative voicing, such as hou[s] $e_{\mathrm{N}} \sim h o u[\mathrm{z}] e_{\mathrm{v}}$. The stress pattern and the fricative-voicing pattern tested in this experiment can therefore be called morphologically supported, since they correspond to a phonological contrast that serves to distinguish actual noun/verb minimal pairs in English.

Crucially, not all of the vowel-backness pairs tested in this experiment, which were [u:] [i:], [ov] [er], and [a] [æ] (see Appendix A for a full list of stimuli), are morphologically supported. While there are actual noun/verb pairs of English with the [u:] [i:] pattern, such as

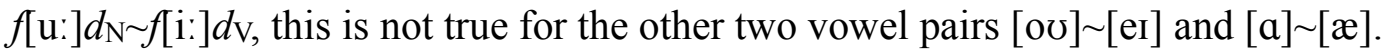

These facts lead to the question: Is the productive knowledge of the noun/verb asymmetries in stress, fricative voicing, and vowel backness found in this experiment truly due to the existence of phonological asymmetries in the lexicon? Or is this knowledge productive only because it is morphologically supported in the case of stress and fricative voicing, and to a lesser extent ([u:] [i:] items only) for vowel backness? The alternative hypothesis would be consistent with the finding that the vowel-backness effect is not as strong as the other two, since only a subset of the vowel-backness items are morphologically supported. 
This question can be explored to some extent by looking for evidence of productive knowledge in the subset of the vowel-backness items that are not morphologically supported, namely, the eight nonce-word pairs involving the vowels [oひ] [eI] and $[a] \sim[æ]$.

Table 4 and Figure 3 show the results of a generalized linear mixed model, fit by the Laplace approximation, for the analysis of the non-morphologically supported items only (by response, as in $\S 3.1$ for the full data set). This analysis models the probability that a given response will conform to the noun/verb pattern in the lexicon of English, such that back-vowel items are more likely to be labeled as nouns and front-vowel items as verbs than the reverse. Items and participants are included as random effects.

\begin{tabular}{|c|c|c|c|c|c|c|c|}
\hline & conforming & non-conforming & Estimate & Std. Error & \multicolumn{3}{|c|}{$z$ value $\operatorname{Pr}(>|z|)$} \\
\hline Non-morph & $367(57.3 \%)$ & $273(42.7 \%)$ & 0.3379 & 0.1849 & 1.827 & \multicolumn{2}{|c|}{$p=0.0677$} \\
\hline$A I C$ & $\log L i k$ & deviance & \multicolumn{5}{|c|}{ Random effects: } \\
\hline 854.2 & -424.1 & 848.2 & Groups & Name & & Variance & Std.Dev. \\
\hline \multirow{2}{*}{\multicolumn{3}{|c|}{$\begin{array}{l}\text { Number of observations: } 640 \text {, } \\
\text { participants, } 80 \text {; items, } 8\end{array}$}} & \multirow{2}{*}{$\begin{array}{l}\text { participants } \\
\text { items }\end{array}$} & \multirow{2}{*}{\multicolumn{2}{|c|}{$\begin{array}{l}\text { (Intercept) } \\
\text { (Intercept) }\end{array}$}} & 0.4817 & 0.6941 \\
\hline & & & & & & 0.1662 & 0.4077 \\
\hline
\end{tabular}

Table 4: Generalized linear mixed model, fit by the Laplace approximation, for the analysis by response (non-morphological items only).

\section{Proportion of conforming responses}

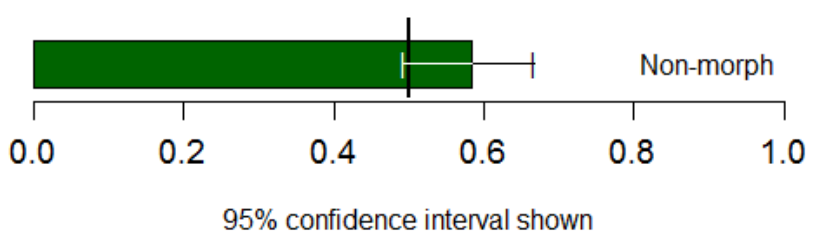

Figure 3: Results by response (non-morphological items only). The coefficient estimate and standard error from the logistic-regression model (see Table 4) were used to derive $95 \%$ confidence intervals for the coefficient; logits were then converted to proportions.

As Table 4 and Figure 3 show, the responses were more likely to map the vowel-backness pattern to a noun/verb pair as predicted by the asymmetry in the lexicon than the reverse. This effect is only marginally statistically significant, but it is worth noting that the subset of the data set containing only the non-morphologically supported items is also considerably smaller than the full data set (640 vs. 2880 observations, or a ratio of 1:4.5).

The results of the non-morphologically supported items were also analyzed by participant, as explained in $\S 3.2$ for the whole data set. Figure 4 shows, for each condition, the number of participants who gave $0,1, \ldots, 7$, or 8 conforming responses; majority-conforming participants 
are those with more than 4 conforming responses (green bars), and minority-conforming participants are those with fewer than 4 (gray bars).

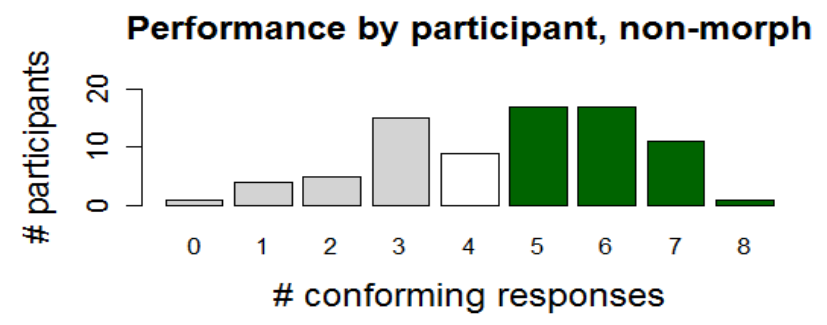

Figure 4: Number of participants who gave $0,1, \ldots, 7$, or 8 responses for nonmorphologically supported items that conform to the noun/verb asymmetry in the lexicon of English.

Table 5 presents the results of an exact binomial test comparing the proportion of majorityconforming versus minority-conforming participants. (As above, participants with exactly 4, or $50 \%$, conforming responses are not informative and are therefore not included in this analysis.)

\begin{tabular}{lrrrr}
\hline Condition & $\begin{array}{c}\text { Majority } \\
\text { conforming }\end{array}$ & $\begin{array}{c}\text { Minority } \\
\text { conforming }\end{array}$ & $\begin{array}{c}\text { Proportion } \\
\text { majority-conforming }\end{array}$ & $p$ \\
\hline Non-morphological & 46 & 25 & 0.58 & 0.0085 \\
\hline
\end{tabular}

Table 5: Number of participants who gave a majority of responses (vs. a minority) for non-morphologically supported items that conform to the pattern of noun/verb asymmetries in the lexicon of English. The $p$ value is from an exact binomial test (one-tailed).

The results summarized in Table 5 show that more participants matched the pattern to a noun/verb pair as predicted by the vowel-backness asymmetry in the lexicon of English than would be expected due to chance. Although the effect is not as strong as in the full data set, these results do still provide evidence for a phonological effect of vowel backness on noun/verb category assignment, confirming that the segmental noun/verb asymmetry of vowel backness seen in the lexicon of English is part of the productive phonological knowledge of English speakers.

As for why the vowel-backness effect is nevertheless not as strong as the stress effect, it may be the case that patterns that are also morphologically supported are more productive than those that are only phonological. Or, an alternative possibility is that the productivity of a given phonological pattern of noun/verb asymmetry depends in part on how extreme the asymmetry is; a comparison of (3) with (2) shows that the lexical evidence for the noun/verb asymmetry involving vowel backness, while statistically significant, is small in magnitude compared to the lexical evidence for the stress asymmetry.

4. Summary, conclusions, and implications. This experiment investigated whether participants would assign the members of a minimal pair that contrasted in stress, in fricative voicing, or in vowel backness to the categories noun and verb in accordance with noun/verb asymmetries in the English lexicon - a measure of whether English speakers' knowledge of the category-sensitive 
phonological asymmetries in the lexicon concerning these three properties is productive, and in particular, whether knowledge of the segmental properties (fricative voicing and vowel backness) is as productive as knowledge of the prosodic property (stress).

In the full data set, all three phonological patterns had an effect significantly greater than chance on how participants assigned nonce words to the categories noun and verb. These results were significant both by overall responses and in an analysis that evaluated the proportion of majority-conforming participants. The stress condition, a control, replicated previous findings (Kelly 1988; Guion et al. 2003) that trochaic nonce-words (versus iambs) are more likely to be labeled as nouns. Crucially, a noun-preference effect was also found for [-voice] final fricatives (versus [+voice]), and for [+back] stressed vowels (versus [-back]). That is, English speakers have productive knowledge of noun/verb asymmetries involving not only prosodic properties, but also segmental properties - even though the cross-linguistic typology of attested categorical noun/verb phonotactic differences is very strongly biased toward prosodic properties.

The results for stress and for fricative voicing in this experiment were very similar, but the results for vowel backness were marginally weaker than those for stress. This suggests that the status of a pattern as morphologically supported (which groups together stress and fricative voicing versus vowel backness) is more influential than the status of a pattern as segmental or prosodic (which groups together fricative voicing and vowel backness versus stress). However, when the non-morphologically supported items - a subset of the vowel-backness items - were analyzed by themselves, they still showed an effect greater than chance, although not as strongly: the analysis by participant was statistically significant, but the analysis by responses was only marginally statistically significant. This difference between the analysis by participant and the analysis by response seems to indicate that more participants than expected by chance show a relatively weak effect of vowel backness in non-morphological items (see Figure 4). What is crucial here, though, is that even the non-morphologically supported items did affect the assignment of nonce words to the categories noun and verb, which is evidence of productive knowledge of this phonological asymmetry even in the absence of morphological support.

Further investigation is needed to confirm the role of morphological support in speakers' productive knowledge of noun/verb asymmetries, however. For one thing, it is possible that the nature of the task in this experiment-direct comparison of minimal pairs, and explicit assignment to the category labels noun and verb - may have encouraged participants to think about potential morphological relationships more than they would have done when performing other kinds of tasks. Also, the lexical evidence for a noun/verb asymmetry in stress (see (2)) is stronger than that for a noun/verb asymmetry in vowel backness (see (3)), so it might be the case that it is the degree of lexical asymmetry, rather than the presence or absence of morphological support, that actually influences the productivity of a pattern. Finally, the non-morphologically supported items in this experiment were a relatively small subset, and they were examined independently only in a post-hoc statistical analysis, so it is not really possible to directly compare the degree of productivity of the patterns that are and are not morphologically supported. For these reasons, it would be instructive to conduct an experiment that compared the productivity of prosodic and segmental asymmetries while explicitly controlling for the morphologically supported status of phonological patterns, using in addition a range of experimental tasks that direct more and less explicit attention to morphological relationships between individual nouns and verbs. 
The results of this study (especially if they can be further confirmed by follow-up experiments) have implications for our understanding of category-sensitive phonological differences. In particular, the fact that English speakers have productive knowledge of not only prosodic, but also segmental, noun/verb differences is evidence that the typological asymmetry favoring prosodic patterns in category-specific phonology does not directly reflect a learning bias; segmental noun/verb differences can indeed be learned. We need to look elsewhere to understand the typological facts about category-specific phonology: for example, is there a difference between prosodic and segmental patterns in pattern complexity, or in the kinds of evidence learners can access in the input, that has the effect of making prosodic noun/verb asymmetries easier to acquire from natural ambient-language data?

Even more generally, then, these findings also have implications for our understanding of the sources of phonological typology. The example of the typological bias toward categorysensitive phonological patterns that are prosodic rather than segmental adds to the growing body of examples of gaps in typology that do not correspond to unlearnable patterns, and so must arise for other reasons.

Appendix A. Experiment stimuli.

\begin{tabular}{|c|c|c|c|c|c|}
\hline \multicolumn{2}{|c|}{ Fricative voicing } & \multicolumn{2}{|c|}{ Vowel backness } & \multicolumn{2}{|r|}{ Stress } \\
\hline N-like & V-like & N-like & V-like & Form & Source \\
\hline $\operatorname{sl} \mathbf{x} \underline{\underline{f}}$ & $\operatorname{sl}^{3} \underline{\mathbf{v}}$ & glu:. & gli:.I & p3r.noI & Kelly (1988), pernor \\
\hline plef & ple $\underline{\mathbf{v}}$ & spü:t & spi:t & pel.tækt & Kelly (1988), peltact \\
\hline $\operatorname{sp}^{2} \underline{\boldsymbol{\theta}}$ & $\operatorname{sp} 3 \underline{\partial}$ & bıoup & bıeip & for.mænd & Kelly (1988), formand \\
\hline $\mathrm{II} \underline{\theta}$ & II & toub & teIb & pan.sckt & Kelly (1988), ponsect \\
\hline $\mathrm{d} \boldsymbol{\mathrm { d }} \Lambda \underline{\mathbf{s}}$ & $\mathrm{d} \boldsymbol{\Lambda} \Lambda \underline{\mathrm{z}}$ & pạg & pæg & fan.tuein & Kelly (1988), fontrain \\
\hline stII & stIz & swâk & swæk & tol.vu:t & Kelly (1988), torvoot \\
\hline 'ses.nIf & 'ses.nIV & 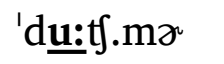 & 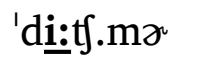 & koul.vein & Kelly (1988), colvane \\
\hline$m 3^{3} \cdot \mathbf{z} \Lambda \underline{\mathbf{f}}$ & $\mathrm{m} 3^{n} \cdot \mathrm{z} \Lambda \underline{\mathbf{v}}$ & nx'.tuu:n & nəా.'tui:n & beI.tist & Guion et al. (2003) \\
\hline 'bal.kıع $\underline{\theta}$ & 'bal.kuع无 & 'skoum.dr' & 'skeim.dx' & tai.gept & Guion et al. (2003) \\
\hline fes.'g $\boldsymbol{\Lambda} \underline{\boldsymbol{\theta}}$ & 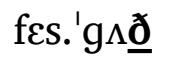 & ləu.'snoud & 1ว.'sneigh & gi:.kips & Guion et al. (2003) \\
\hline 'd3a.kes & 'd $3^{n} \cdot \mathrm{k} \varepsilon \underline{z}$ & 'maz.gð' & 'mæzz.gð & pou.bekt & Guion et al. (2003) \\
\hline sal.'t ţa & sal.'t $\int 3^{x} \underline{z}$ & pr.'\$gad & pr.'\$æג & tu:.minz & Guion et al. (2003) \\
\hline
\end{tabular}


Appendix B. Experiment instructions and example trial.

(5) Experiment instructions

\section{Welcome}

This survey is part of an experiment about how speakers of English decide whether an unfamiliar word is a noun or a verb.

First, we will ask you to practice identifying real English words as nouns or verbs. You must get all three practice questions correct to continue with the survey. The practice questions are not hard if you are comfortable with real nouns and verbs in English.

Then, we will ask you to listen to "new" words of English (which we have created for this survey) and decide which are nouns and which are verbs. There will be 36 pairs of words to judge, and it will take you about 6 minutes to listen to them all.

(6) Example trial

\section{Which word is which?}

Listen to these two words as many times as you like. Then decide which is the noun and which is the verb.

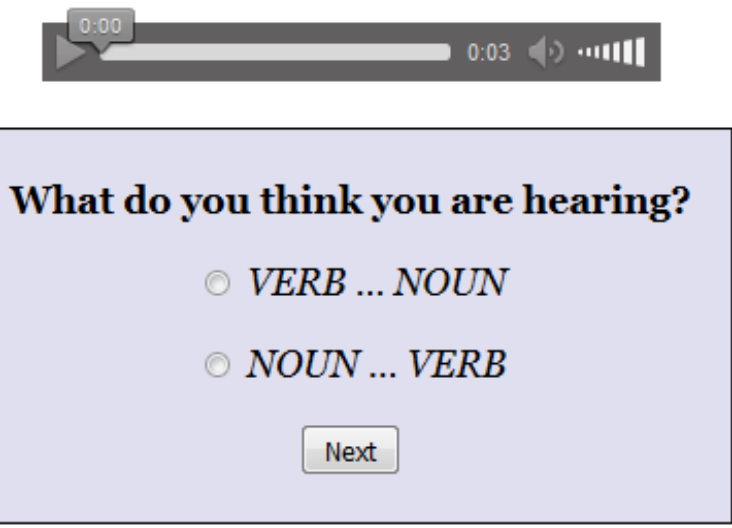

\section{References}

Albright, Adam. 2008. How many grammars am I holding up? In Charles B. Chang \& Hannah J. Haynie (eds.), Proceedings of the West Coast Conference on Formal Linguistics 26. 1-20. Malden, MA: Cascadilla Proceedings Project. http://www.lingref.com/cpp/wccfl/26/abstract1651.html.

Ansre, Gilbert. 1961. The tonal structure of Ewe. Hartford, CT: Hartford Studies in Linguistics. 
Baayen, R. H., R. Piepenbrock, \& L. Gulikers. 1995. CELEX2 LDC96L14 [lexical database]. Philadelphia: Linguistic Data Consortium. https://catalog.ldc.upenn.edu/LDC96L14.

Becker, Michael. 2003. Lexical stratification of Hebrew: The disyllabic maximum. In Yehuda N. Falk (ed.), Proceedings of the Israel Association for Theoretical Linguistics 19. http://linguistics.huji.ac.il/IATL/19/Becker.html.

Becker, Michael, Nihan Ketrez, \& Andrew Nevins. 2011. The surfeit of the stimulus: Analytic biases filter lexical statistics in Turkish laryngeal alternations. Language 87. 84-125. http://dx.doi.org/10.1353/lan.2011.0016.

Berg, Thomas. 2000. The position of adjectives on the noun-verb continuum. English Language and Linguistics 4. 269-293.

Bobaljik, Jonathan David. 1998. Mostly predictable: Cyclicity and the distribution of schwa in Itelmen. In Vida Samiian (ed.), Proceedings of WECOL 1996. 14-28. Fresno: CSU Fresno. http://www.fresnostate.edu/artshum/linguistics/documents/WECOL \%201996\%20VOLUME\%209.pdf.

Bobaljik, Jonathan David. 2008. Paradigms (Optimal and otherwise): A case for skepticism. In Asaf Bachrach \& Andrew Nevins (eds.), Inflectional identity. 29-54. Oxford: Oxford University Press.

Chomsky, Noam, \& Morris Halle. 1968. The sound pattern of English. New York: Harper \& Row.

Crowley, Terry. 1997. An introduction to historical linguistics, 3rd edn. Oxford: Oxford University Press.

Devine, A.M., \& Laurence D. Stephens. 1994. The prosody of Greek speech. New York: Oxford University Press.

Dixon, R.M.W. 1991. Mbabaram. In R.M.W. Dixon \& Barry J. Blake (eds.), Handbook of Australian languages, vol. 4. 348-402. Melbourne: Oxford University Press.

Francis, W. Nelson, \& Henry Kučera. 1982. Frequency analysis of English usage: Lexicon and grammar. Boston: Houghton Mifflin.

Goodenough, Ward H., \& Hiroshi Sugita. 1980. Trukese-English dictionary. Philadelphia: American Philosophical Society.

Guion, Susan G., J. J. Clark, Tetsuo Harada, \& Ratree P. Wayland. 2003. Factors affecting stress placement for English nonwords include syllabic structure, lexical class, and stress patterns of phonologically similar words. Language and Speech 46. 403-426. http://dx.doi.org/10.1177/00238309030460040301.

Harris, James. 1983. Syllable structure and stress in Spanish. Cambridge, MA: MIT Press.

Jaber, Aziz. 2011. High-vowel syncope in Jordanian Arabic: A Positional Faithfulness treatment. Chapel Hill: University of North Carolina, ms.

Jespersen, Otto. 1942. A Modern English grammar on historical principles, vol. 6. London: Allen \& Unwin.

Kelly, Michael H. 1988. Phonological biases in grammatical category shifts. Journal of Memory and Language 27. 343-358. http://dx.doi.org/10.1016/0749-596X(88)90060-5.

Kelly, Michael H. 1992. Using sound to solve syntactic problems: The role of phonology in grammatical category assignments. Psychological Review 99. 349-364. http://dx.doi.org/10.1037/0033-295X.99.2.349.

Kisseberth, Charles, \& David Odden. 2003. Tone. In Derek Nurse \& Gérard Phillipson (eds.), The Bantu languages. 59-70. London: Routledge. 
Krause, Scott. 1979. Topics in Chukchee phonology and morphology. Urbana-Champaign: University of Illinois dissertation.

Kubo, Tomoyuki. 2008. A sketch of Sibe phonology. Gogaku kenkyuu fooramu 16. 127-142.

Lynch, John D. 1975. Lenakel phonology. University of Hawaii Working Papers in Linguistics 7(1). i-vii and 1-244.

Lynch, John D. 1978. A grammar of Lenakel. (Pacific Linguistics B55.) Canberra: Australian National University.

McCawley, James D. 1968. The phonological component of a grammar of Japanese. The Hague: Mouton.

Moreton, Elliott, Jennifer L. Smith, Katya Pertsova, Rachel Broad, \& Brandon Prickett. 2016. Emergent positional privilege in novel English blends. Chapel Hill: University of North Carolina, ms.

http://www.unc.edu/ jlsmith/home/pdf/MoretonSmithPertsovaBroadPrickett2016revised.p df.

Muller, Jennifer S. 1999. A unified mora account of Chuukese. In Sonya Bird, Andrew Carnie, Jason D. Haugen, \& Peter Norquest (eds.), Proceedings of the West Coast Conference on Formal Linguistics 18. 393-405. Malden, MA: Cascadilla Press.

O'Hara, Charlie. To appear. Positionally abstract underlying representations in Klamath. Proceedings of Chicago Linguistic Society 51.

Olson, Kenneth S. 2005. The phonology of Mono. Dallas: SIL International.

Postal, Paul M. 1968. Aspects of phonological theory. New York: Harper and Row.

Ryding, Karin C. 2005. A reference grammar of Modern Standard Arabic. Cambridge: Cambridge University Press.

Sereno, Joan A., \& Allard Jongman. 1990. Phonological and form class relations in the lexicon. Journal of Psycholinguistic Research 19. 387-404. http://dx.doi.org/10.1007/BF01068886.

Smith, Jennifer L. 2011. Category-specific effects. In Marc van Oostendorp et al. (eds.), The Blackwell Companion to Phonology. 2439-2463. Malden, MA: Wiley-Blackwell.

Smith, Jennifer L. 2014. Prosody vs. segments in laboratory learning of category-specific phonology. 2014 Annual Meeting of the Linguistics Association of Great Britain. http://www.unc.edu/ jlsmith/home/pdf/smith2014_LAGB2014_poster.pdf.

Sprouse, Jon. 2011. A validation of Amazon Mechanical Turk for the collection of acceptability judgments in linguistic theory. Behavior Research Methods 43. 155-167. http://dx.doi.org/10.3758/s13428-010-0039-7.

Walker, Douglas C. 1984. The pronunciation of Canadian French. Ottawa: University of Ottawa Press.

Whitman, John. 1994. The accentuation of nominal stems in Proto-Korean. In Young-Key KimRenaud (ed.), Theoretical issues in Korean linguistics. 425-439. Stanford: CSLI.

Wolff, Ekkehard. 1983. A grammar of the Lamang language. Glückstadt: Verlag J.J. Augustin. 